\title{
Overexpression of SOX4 promotes cell migration and invasion of renal cell carcinoma by inducing epithelial-mesenchymal transition
}

\author{
HAILONG RUAN $^{1}$, HONGMEI YANG ${ }^{2}$, HAIBIN WEI $^{3}$, WEN XIAO $^{1}$, NING LOU $^{1}$, \\ BIN QIU ${ }^{1}$, GUANGHUA XU ${ }^{1}$, ZHENGSHUAI SONG ${ }^{1}$, HAIBIN XIAO ${ }^{1}$, LEI LIU ${ }^{1}$, \\ YALI ZHOU ${ }^{2}$, WENJUN HU ${ }^{2}$, KE CHEN ${ }^{1}$, XUANYU CHEN ${ }^{1,3,4}$ and XIAOPING ZHANG ${ }^{1}$ \\ ${ }^{1}$ Department of Urology, Union Hospital, Tongji Medical College, Huazhong University of Science and \\ Technology, Wuhan 430022, China; ${ }^{2}$ Department of Pathogenic Biology, School of Basic Medicine, \\ Huazhong University of Science and Technology, Wuhan, Hubei 430030; ${ }^{3}$ Department of Urology, \\ Zhejiang Provincial People's Hospital, Hangzhou, Zhejiang 310014, P.R. China; ${ }^{4}$ Department of Neuroscience \\ and Regenerative Medicine, Medical College of Georgia, Augusta University, Augusta, GA 30912, USA
}

Received March 15, 2017; Accepted May 8, 2017

DOI: 10.3892/ijo.2017.4010

\begin{abstract}
Incomplete understanding remains in the molecular mechanisms underlying progression and metastasis of renal cancer. The transcription factor SOX4 is upregulated in various human malignancies, including renal cancer, indicating it may be involved in renal tumorigenesis. In this study, we explored this hypothesis by loss-of-function and gain-of-function assays of SOX4 in renal cancer cell lines and renal epithelial cell line. We found that specific knockdown of SOX4 in renal cancer cell lines significantly suppressed the migration and invasion of cancer cells; specific overexpression of SOX4 in renal epithelial cell line markedly promoted the migration and invasion of the cell line. Epithelial-mesenchymal transition (EMT), a fundamental morphogenesis process, is implicated in renal cancer progression and metastasis. Our results demonstrated that $\mathrm{SOX} 4$ positively regulated the expression of mesenchymal cell markers and negatively regulated the expression of epithelial cell marker, and was involved in signal transduction pathway of TGF $\beta$-induced EMT. In addition, SOX4 induced EMT probably through modulating the AKT/p-AKT signaling cascade. Finally, we found that SOX4 was significantly upregulated in clinical renal cancer samples compared with corresponding normal tissues and associated
\end{abstract}

Correspondence to: Dr Xuanyu Chen, Department of Urology, Zhejiang Provincial People's Hospital, 158 Shangtang Road, Hangzhou, Zhejiang 310014, P.R. China

E-mail: xuachen@augusta.edu

Professor Xiaoping Zhang, Department of Urology, Union Hospital, Tongji Medical College, Huazhong University of Science and Technology, 1277 Jiefang Avenue, Wuhan, Hubei 430022, P.R. China E-mail: xzhang@hust.edu.cn

Key words: SOX4, metastasis, epithelial-mesenchymal transition, AKT, p-AKT, renal cell carcinoma with EMT process in clinical samples. Taken together, our findings confirm a crucial function of SOX4 in the metastasis of renal cancer through orchestrating EMT and establish that the function suppression of SOX4-AKT-EMT axis might be an attractive therapeutic intervention during renal cancer metastasis.

\section{Introduction}

Renal cell carcinoma (RCC) accounting for $80-90 \%$ renal malignancies derives from renal tubule epithelium, which is also called renal adenocarcinoma. It is estimated that approximately 62,700 new cases of renal cancer and 14,240 deaths from renal cancer occurred in the United States in 2016 (1). According to $2004 \mathrm{WHO}$ histopathological classification criteria, RCC was classified into a variety of histologic subtypes. Clear cell RCC (ccRCC) represents the most common subtype of RCC that is characterized by high frequency of metastasis and mortality, and resistance to traditional radiotherapy and chemotherapy. Cancer metastasis is the overwhelming cause of tumor-related mortality in tumor-bearing patients (2-4). Unfortunately, approximately $30 \%$ of patients with renal cancer have developed local invasion or distant metastasis when diagnosed, resulting in poor prognosis. Currently, the underlying molecular mechanisms of metastasis of renal cell carcinoma are elusive. Therefore, it is greatly needed to make a thorough inquiry of metastatic mechanisms in RCC, aiming to provide a novel target for clinical treatment.

Epithelial-mesenchymal transition (EMT), a fundamental morphogenesis process in which the epithelial cells transform into motile mesenchymal cells, plays a pivotal role in embryogenesis $(5,6)$, the formation of organs, the differentiation of tissues, wound healing, stem cell property, and malignant tumor progression and metastasis $(7,8)$. During an EMT process, epithelial cells lose their characteristics, such as the loss of cell polarity, cell-cell adhesion, and downregulation of epithelial markers, substituted by mesenchymal cell 
traits involving acquisition of migration and invasiveness, resistance to apoptosis and senescence, stemness and immunosuppression, and upregulation of mesenchymal markers (7).

SOX4, belonging to the sex-determining region Y (SRY)related high-mobility group (HMG)-box family, is a crucial transcriptional factor associated with a series of development procedures, such as retinal differentiation, central nervous system, heart development, lymphocyte development, via its transcriptional activation (9-14). Recently, SOX4, as an oncogenic gene, has aroused great interest of researchers, and has been implicated in various human malignancies, including leukemia (15), cancers of lung (16), prostate (17), liver (18), colon (19), breast (3), and ovarian (20). In breast cancer and prostate cancer, SOX4 can induce epithelial-mesenchymal transition and promote metastasis $(21,22)$. In a few human malignancies, however, SOX4 has been classified as a tumor suppressor gene, including gallbladder cancer (23), bladder cancer (24), and glioblastoma multiforme (25). However, few studies have been carried out to investigate SOX4 expression in renal cell carcinoma and its biological behavior in renal cancer cells. TGF $\beta$ signaling transduction pathway has been reported to be involved in EMT and malignancies progression (26). Moreover, TGF $\beta$ signaling has been demonstrated to induce SOX4 expression in breast cancer and prostate cancer $(21,22)$. Thus, we conjectured that SOX4 might play a catalytic role in the progression and metastasis of RCC via induction of EMT.

In this study, we verified SOX4 overexpression in renal cancer tissues and cell lines. Downregulation of SOX4 greatly inhibited the migratory and invasive abilities of renal cancer cells 786-O and SN12-PM6, while overexpression of SOX4 strongly increased the migratory and invasive properties of the immortalized non-transformed renal HK-2 cells. Besides, the gain or loss of SOX4 expression could partly induce or reverse the EMT process, respectively, and upregulate or downregulate the expression of phospho-AKT (p-AKT) in renal cancer cells. Therefore, we speculated that SOX4 might play a role in renal cancer cell migration and invasiveness by inducing EMT through AKT/p-AKT signaling cascade. These data indicated that SOX4 might be an oncogenic gene through orchestrating EMT in RCC tumor microenvironment and provided a firm theoretical principle for consideration of SOX4 as a target for therapy of RCC.

\section{Materials and methods}

Human renal cancer samples. All samples (paired tumor and normal tissues) were surgically resected from patients with RCC between 2012 and 2014, at Union Hospital of Huazhong University of Science and Technology (Wuhan, China). Resected tissues were immediately frozen in liquid nitrogen for subsequent experiments. None of the patients had received any antitumor therapy before surgery. Informed written consent was obtained from each of the RCC patients. This study and experiment procedures were approved by the Institutional Review Board of Huazhong University of Science and Technology.

Cell culture. All cell lines were cultured in Dulbecco's Modified Eagle Medium (DMEM) (Invitrogen, Carlsbad, CA,
USA) containing $10 \%$ fetal bovine serum (Gibco-BRL, Grand Island, NY, USA), and $1 \%$ penicillin-streptomycin at $37^{\circ} \mathrm{C}$ in a humidified $5 \% \mathrm{CO}_{2}$ atmosphere. For TGF $\beta 1$ treatment, the HK-2 cells were cultured in DMEM containing $10 \%$ fetal bovine serum, and $1 \%$ penicillin-streptomycin and treated with $2.5 \mathrm{ng} / \mathrm{ml}$ of TGF $\beta 1$ for $0,3,7,10$ day(s), respectively.

Transient transfection assay. The si-RNA duplexes targeting SOX4 (si-SOX4) and si-RNA Negative Control (si-NC) were synthesized and purified by GenePharma (Shanghai, China). All si-RNA sequences were subjected to BLAST analysis to guarantee that there is no homology to any other known coding sequences in the Human Genome Database. The si-SOX4 and si-NC were transfected at a final concentration of $50 \mathrm{nM}$ with Lipofectamine 2000 reagent (Invitrogen) according to the manufacturer's recommendations. The plasmid vectors expressing SOX4 (SOX4) or Negative Control (NC) were constructed by Vigene Biosciences (Shandong, China). A total $2 \mu \mathrm{g}$ of SOX4 or NC plasmid were transfected with Lipofectamine 2000 reagent (Invitrogen) according to the manufacturer's recommendations. At $48 \mathrm{~h}$ after transfection, cells were harvested for subsequent experiments. The si-RNA sequences were as follows: si-SOX4 \#1: 5'-UUUGCC CAGCCGCUUGGAGAUCUCG-3', si-SOX4 \#2: 5'-UUGUC GCUGUCUUUGAGCAGCUUCC-3', si-NC: 5'-UUCUCCG AACGUGUCACGUTT-3'.

Immunohistochemistry assay. Immunohistochemistry (IHC) assay was performed as previously described (27). Briefly, RCC tissues and corresponding normal tissues were fixed in $10 \%$ formalin, dehydrated, and embedded in paraffin sequentially. The sections were incubated with rabbit polyclonal antibody SOX4 (1:100, ab80261, Abcam, Cambridge, MA, USA) overnight at $4^{\circ} \mathrm{C}$. After washing three times with PBS for 10 min each time, the sections were incubated with anti-rabbit secondary antibodies conjugated to horseradish peroxidaselabeled polymers. Finally, the sections were counterstained with hematoxylin.

Immunofluorescence. Appropriate amounts of cells were seeded on glass coverslips in 12-well plates, washed with PBS three times, fixed in $4 \%$ paraformaldehyde and permeabilized with $0.3 \%$ TritonX-100 for $10 \mathrm{~min}$. Cells were blocked with $3 \%$ BSA for $1 \mathrm{~h}$. Grass coverslips were incubated with primary antibodies overnight at $4^{\circ} \mathrm{C}$, followed by incubation with $\mathrm{CY} 3$-conjugated secondary antibodies for $1 \mathrm{~h}$ at room temperature, and then stained with DAPI. After washing with PBS, glass coverslips were photographed under a fluorescence microscope.

Transwell migration and invasion assays and wound healing assays. In vitro cell migration and invasion assays were performed using 24-well Transwell chambers with $8.0-\mu \mathrm{m}$ pore polycarbonate membrane inserts (Corning). For the migration assay, $1 \times 10^{4}$ (786-O, SN12-PM6) or $2.5 \times 10^{4}$ (HK-2) cells were added to the top chambers. For the invasion assay, $2 \times 10^{4}$ (786-O, SN12-PM6) or $5 \times 10^{4}$ (HK-2) cells were added to the top chambers precoated with Matrigel (BD Biosciences, Franklin Lakes, NJ, USA). As a chemoattractant, complete medium supplemented with $10 \%$ FBS was added to the 
A

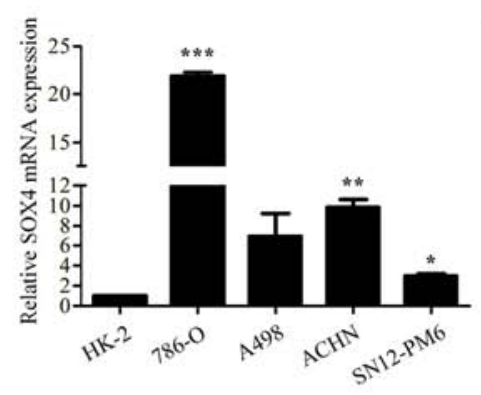

B

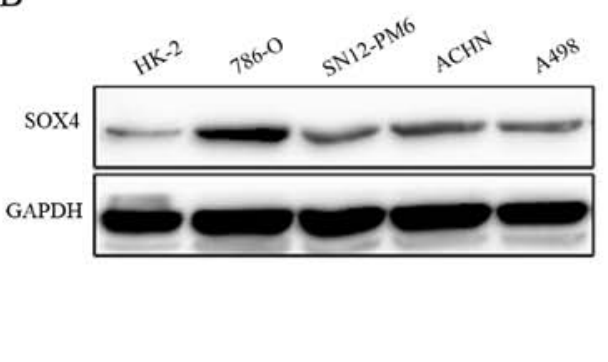

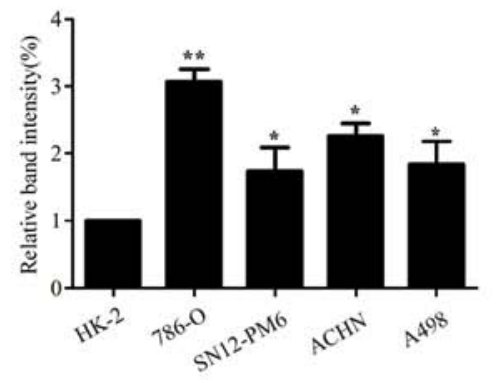

C
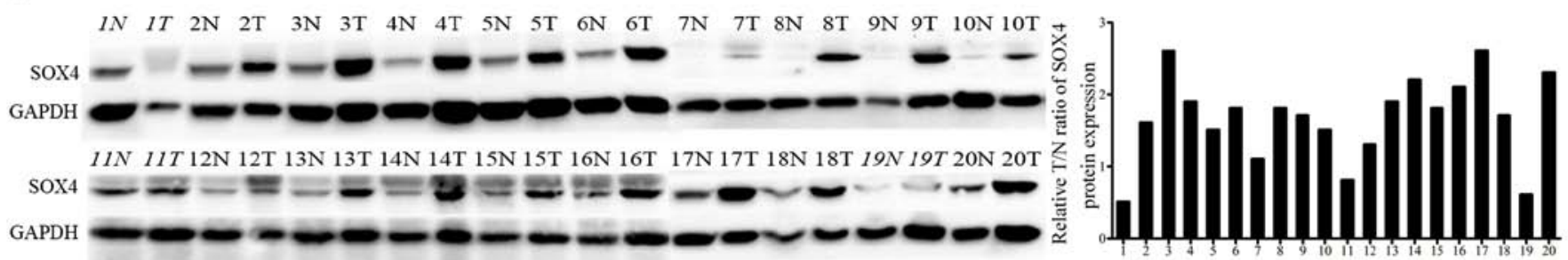

D

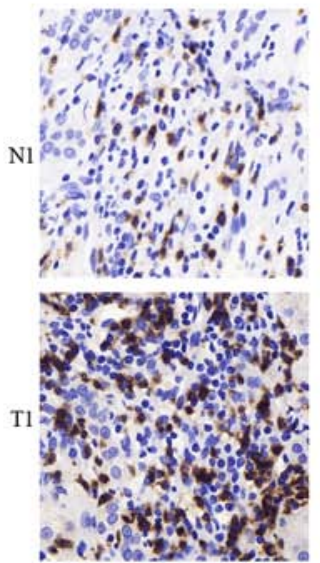

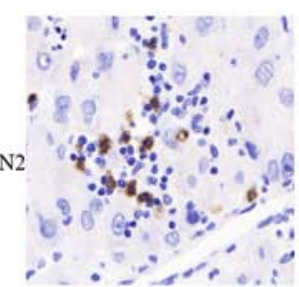

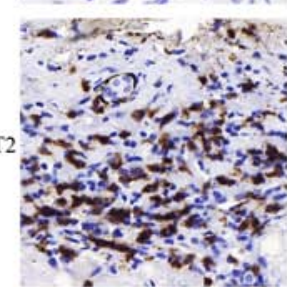

E

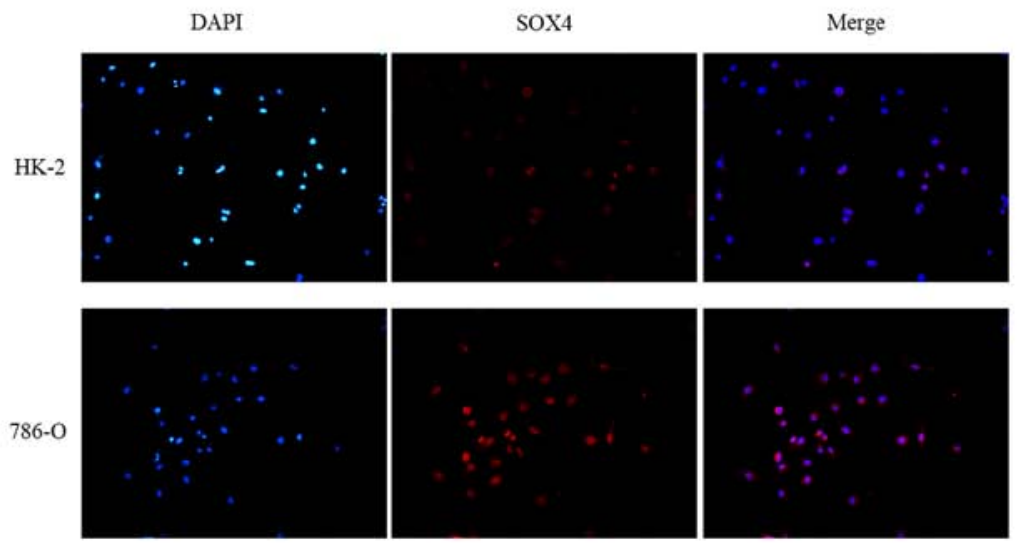

Figure 1. The expression of SOX4 in RCC cell lines and tissues. (A and B) Real-time PCR analysis and western blot assessment of SOX4 expression in 4 human RCC cell lines (786-O, SN12-PM6, ACHN, and A498) and 1 human normal renal tubule epithelial cell line (HK-2). The SOX4 expression was normalized to GAPDH. (C) Immunoblotting analysis of SOX4 expression in 20 paired RCC tissues and corresponding adjacent normal tissues. Upregulation of SOX4 expression was confirmed in 17 of 20 tissue specimens, except 3 pairs of ccRCCs (italics). GAPDH was used as a loading control. (D) Immunohistochemistry (IHC) analysis of SOX4 expression in RCC tissues and adjacent normal tissues. Representative images are displayed. (E) Immunofluorescence analysis of SOX4 expression in 786-O cells and HK-2 cells. Except IHC assay, all experiments were repeated at least three times. Error bars represent mean \pm SEM from three independent experiments $\left({ }^{* * *} \mathrm{P}<0.001,{ }^{* *} \mathrm{P}<0.01,{ }^{*} \mathrm{P}<0.05\right.$, compared with HK-2).

bottom chambers to stimulate migration or invasion. After cells were incubated for $24 \mathrm{~h}$, cells on the top surface of the membrane were gently scraped with a cotton swab and cells on the lower surface of the membrane were fixed with $100 \%$ methanol and then stained with $0.1 \%$ crystal violet. The cells migrating or invading through the membrane were counted in 5 random fields. For wound healing assays, cells transfected with si-RNA were seeded in 6-well plates. When cells reached $70-80 \%$ confluence, a scratch was made using $10-\mu l$ pipette tip, washed, then images were at 0 and $24 \mathrm{~h}$.

Quantitative real-time PCR assays. Total RNA of tissues and cells was extracted by using TRIzol reagent (Invitrogen), and $1 \mu \mathrm{g}$ RNA samples were reverse transcribed to cDNA by using reverse transcriptase M-MLV (Invitrogen). Quantitative realtime PCR (qRT-PCR) was performed using the SYBR-Green PCR master mix (Invitrogen) on a Roche LightCycler 480 system (Roche Diagnostics, Mannheim, Germany). Glyceraldehydes-3-phosphate dehydrogenase (GAPDH) was used as an endogenous control. Relative expression of genes was calculated using the power formula: $2^{-\Delta \mathrm{Ct}}\left(\Delta \mathrm{Ct}=\mathrm{Ct}_{\text {target }}-\mathrm{Ct}_{\text {control }}\right)$, as previously described (28). The gene primer sequences were as follows: SOX4: forward, 5'-GGCCTCGAGCT GGGAATCGC-3', reverse, 5'-GCCCACTCGGGGTCTTG CAC-3';E-cadherin:forward,5'-GACAACAAGCCCGAATT-3', reverse, 5'-GGAAACTCTCTCGGTCCA-3'; N-cadherin: forward, 5'-CGGGTAATCCTCCCAAATCA-3', reverse, 5'-CTTTATCCCGGCGTTTCATC-3'; Vimentin: forward, 5'-GAGAACTTTGCCGTTGAAGC-3', reverse, 5'-GCTTCCT GTAGGTGGCAATC-3'; Twist: forward, 5'-CTGCCCTCG GACAAGCTGAG-3', reverse, 5'-CTAGTGGGACGCGGA CATGG-3'; ZEB1: forward, 5'-TGCTCCCTGTGCAGTTAC ACCTT-3', reverse, 5'-CCAGACTGCGTCACATGTCTT TGA-3'; GAPDH: forward, 5'-GAGTCAACGGATTTGGT CGT-3', reverse, 5'-GACAAGCTTCCCGTTCTCAG-3'.

Western blot assays. Tissues or cells were lysed in RIPA lysis buffer $(50 \mathrm{mM}$ Tris- $\mathrm{HCl}, 150 \mathrm{mM} \mathrm{NaCl}, 1 \%$ Triton 
A

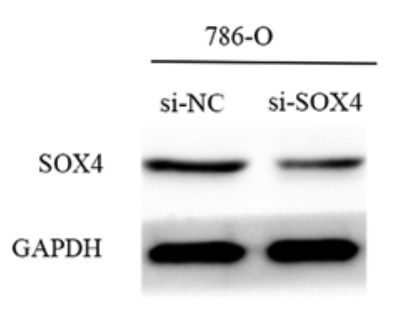

$\mathrm{D}$

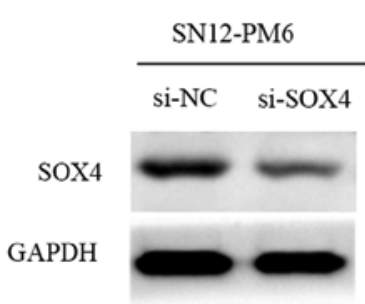

G

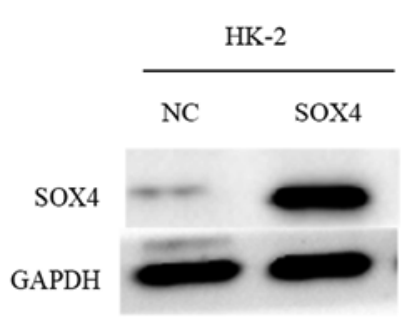

B

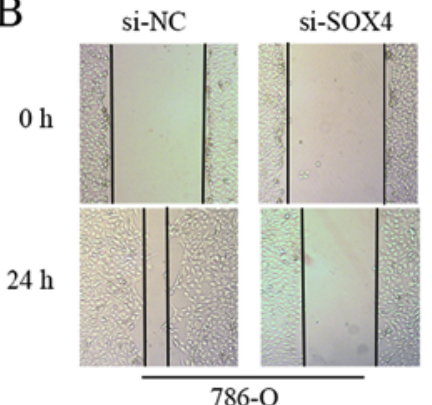

E

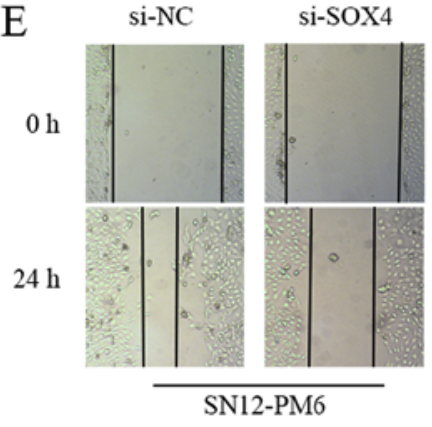

$\mathrm{H}$

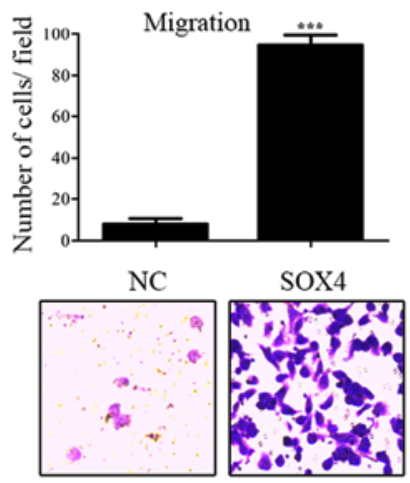

$\mathrm{C}$

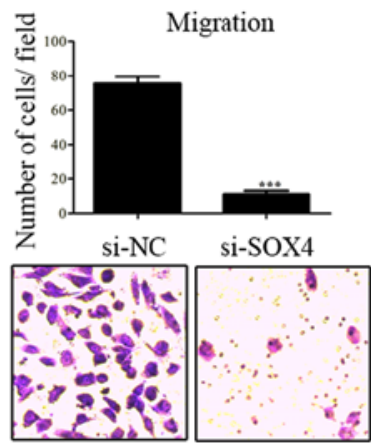

$\mathrm{F}$
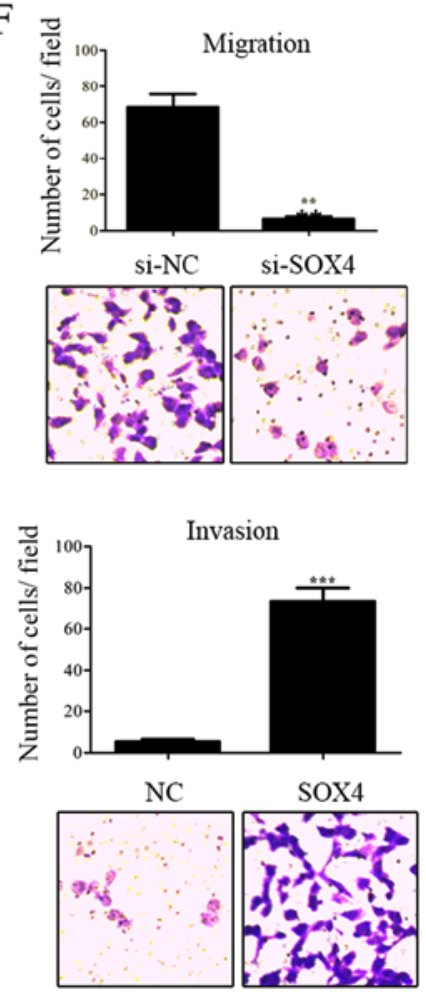
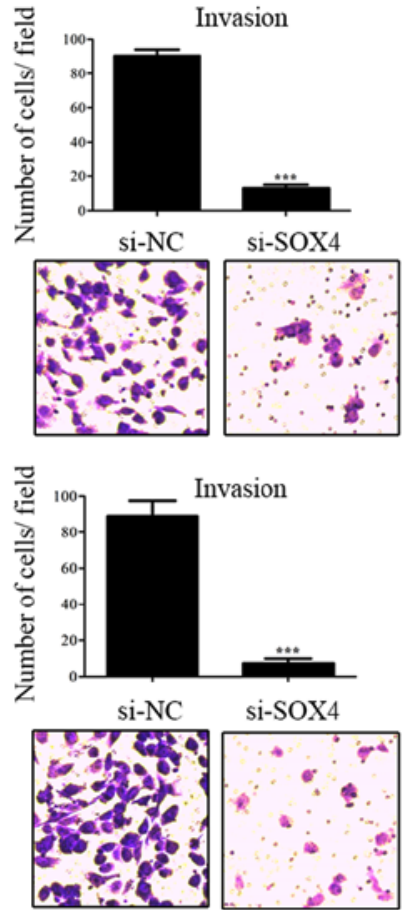

Figure 2. The effects of SOX4 on migration and invasion in 786-O and SN12-PM6 and HK-2 cell lines in vitro. (A-C) Wound healing and migration and invasion assays of 786-O transiently transfected with si-SOX4 or si-NC. (D-F) Wound healing and migration and invasion assays of SN12-PM6 transiently transfected with si-SOX4 or si-NC. (G and H) Migration and invasion assays of HK-2 transiently transfected with SOX4 or NC. The mean number of cells/field was derived from 5 random fields ${ }^{* * *} \mathrm{P}<0.001,{ }^{* *} \mathrm{P}<0.01$, compared with the corresponding control). Each experiment was repeated at least three times. Representative images are displayed.

$\mathrm{X}-100,0.1 \%$ SDS1\% and sodium deoxycholate, $\mathrm{pH} 7.4$ ) containing a protease inhibitor cocktail tablet (Roche Diagnostics) and $1 \mathrm{mM}$ phenylmethylsulfonyl fluoride (PMSF). The lysate protein concentration was measured by using BCA kit (Beyotime Institute of Biotechnology) according to manufacturer's instructions. Total protein $(40 \mu \mathrm{g})$ were subjected to SDS-PAGE electrophoresis and then transferred to a PVDF membrane (Millipore, Bedford, MA, USA). After being blocked in PBS containing 5\% nonfat milk for $1 \mathrm{~h}$, the membranes were incubated with antibody against SOX4, N-cadherin, Vimentin, MMP-9, p-AKT, AKT (all from Abcam), E-cadherin (Cell Signaling Technology, Beverly, MA, USA), Twist, GAPDH (both from Santa Cruz Biotechnology, Inc., Santa Cruz, CA, USA) overnight at $4^{\circ} \mathrm{C}$. The membranes were then incubated with secondary antibody conjugated to horseradish peroxidase for $2 \mathrm{~h}$ at room temperature. After washing with PBS-Tween-20, the proteins were visualized and quanti- fied using ChemiDoc-XRS+ (Bio-Rad, Laboratories, Inc., Hercules, CA, USA).

Statistical analysis. Data were analyzed using GraphPad Prism 5.0 (GraphPad Software, Inc., La Jolla, CA, USA). Comparisons of different groups were performed using Student's two-tailed t-test. Data of each group were expressed as mean \pm SEM and $\mathrm{P}<0.05$ was considered to indicate a statistically significant difference.

\section{Results}

The expression of SOX4 is upregulated in RCC tissues and cell lines. Our previous findings demonstrated low miR129-3p levels were associated with short disease-free and overall survival of RCC patients. miR-129-3p impaired RCC cell migratory and invasive properties by decreased multiple metastasis-related genes, including SOX4 (29). Based on these 

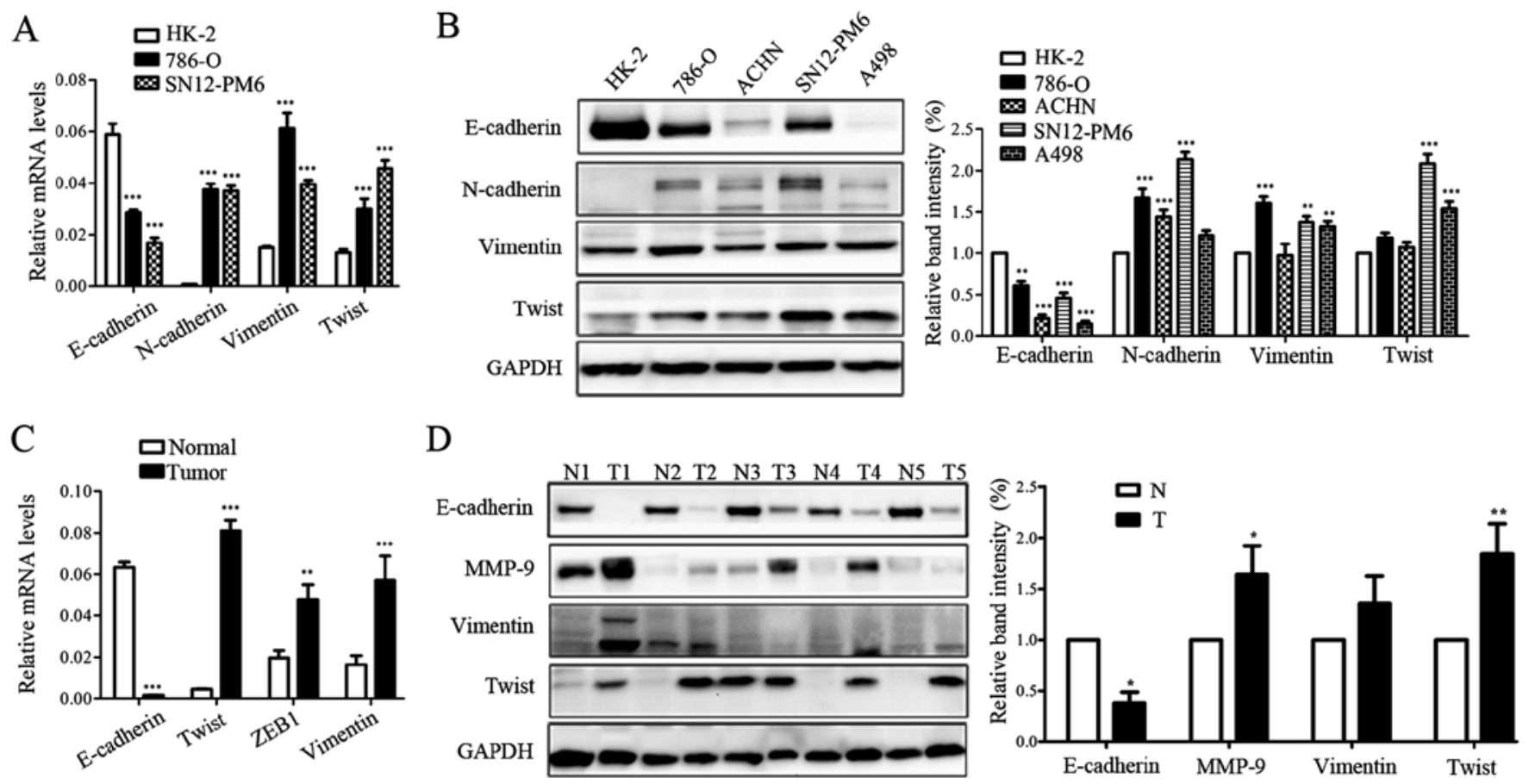

Figure 3. The EMT marker expression in RCC cell lines and tissues. (A and B) The mRNA levels and protein levels of EMT markers in RCC cell lines and normal renal tubule epithelial cell line. GAPDH was used as an internal control. (C and D) The mRNA levels and protein levels of EMT markers in RCC tissues and corresponding adjacent normal tissues. GAPDH was used as an internal control. The data were derived from three independent experiments at least. Error bars represent mean \pm SEM from three independent experiments $\left({ }^{* * *} \mathrm{P}<0.001,{ }^{* *} \mathrm{P}<0.01,{ }^{*} \mathrm{P}<0.05\right.$, compared with the corresponding control).

observations, we first aimed to examine the levels of SOX4 expression in RCC cell lines and tissues by qRT-PCR and western blot analysis. Of note, the levels of SOX4 mRNA and protein expression were dramatically upregulated in RCC cell lines (786-O, SN12-PM6, ACHN and A498) compared with the normal renal epithelial cell line HK-2 (Fig. 1A and B). Unexpectedly, no remarkable difference of SOX4 mRNA was observed between ccRCC and normal tissues. However, RCC tissues exhibited significantly higher SOX4 protein expression in 17 of 20 pairs RCC compared with corresponding normal tissues by western blotting and IHC (Fig. 1C and D). Moreover, immunofluorescence revealed that SOX4 was overexpressed in RCC cells compared with the normal renal cells (Fig. 1E). Collectively, these results indicate SOX4 expression is upregulated in RCC.

The effects of SOX4 on migration and invasion in 786-O and SN12-PM6 and HK-2 cell lines. To explore the roles of SOX4 upregulation in RCC cell lines, we then performed a loss-of-function assay by using small interfering RNA specifically targeting SOX4 (Fig. 2A and D). The effects of SOX4 knockdown on migration and invasion of these two cell lines were examined using wound healing and Transwell chamber assays. The results revealed that SOX4 knockdown markedly undermined the migration and invasion of these two RCC cell lines (Fig. 2B and C, and E and F), however, it did not influence cell proliferation and apoptosis (data not shown). To further confirm the involvement of SOX4 in migration and invasion, we then carried out a gain-of-function assay in HK-2 cell line by constructing plasmid vector expressing SOX4 (Fig. 2G). The results indicated that SOX4 overexpression prominently promoted the migration and invasion of HK2 cell line
(Fig. 2H), but it did not affect cell proliferation and apoptosis (data not shown). In addition, downregulation or upregulation of SOX4 did not cause significant changes in cell morphology. Therefore, our loss-of-function and gain-of-function assays demonstrated that SOX4 might promote migration and invasion in RCC cell lines in vitro.

EMT process exists in RCC tissues and cell lines. Accumulating evidence demonstrates that EMT has been implicated in cancer metastasis $(2,30,31)$. Therefore, in order to investigate the potential metastatic mechanisms in RCC, we examined the EMT marker expression in RCC cell lines and tissues by qRT-PCR and western blotting. As shown in Fig. 3A and B, the RCC cell lines exhibited a significant downregulation of E-cadherin compared with the HK-2 cell line; the mesenchymal cell markers $\mathrm{N}$-cadherin, Twist, and Vimentin were markedly upregulated. Moreover, RCC tissues exhibited a significant downregulation of E-cadherin compared with the corresponding normal tissues; whereas, the mesenchymal markers Vimentin, ZEB1, MMP-9, and Twist were prominently upregulated (Fig. 3C and D). Data above indicated that EMT process might have occurred in the formation and progression of RCC.

The effects of SOX4 on EMT profile in 786-O and SN12-PM6 and $H K-2$ cell lines. Recent studies have identified SOX4 as a master regulator of EMT (32). To explore the potential correlation between SOX4 and EMT in RCC, we successfully knocked down the expression of SOX4 in 786-O and SN12-PM6 cell lines that overexpressed endogenous SOX4, by using small interfering RNA, as confirmed by qRT-PCR and western blotting (Fig. 4A and B). We then examined by 
A

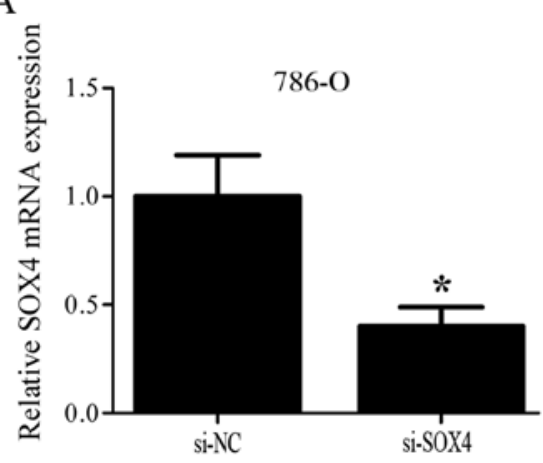

B

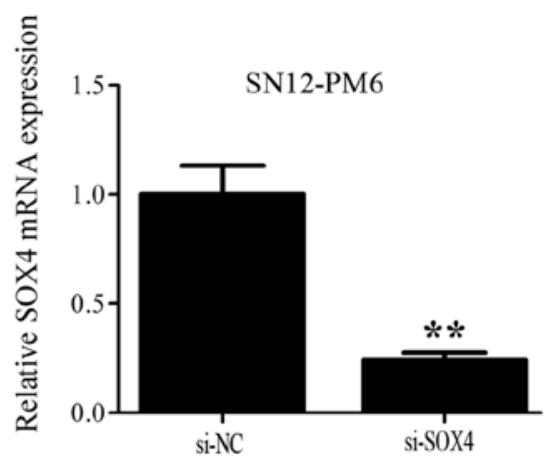

C

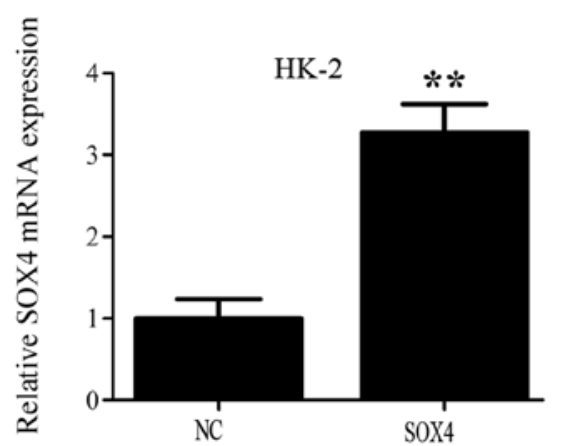

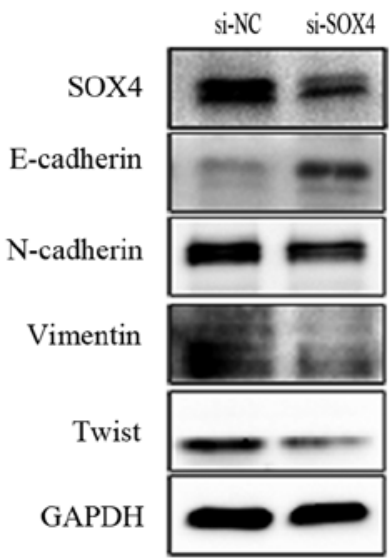

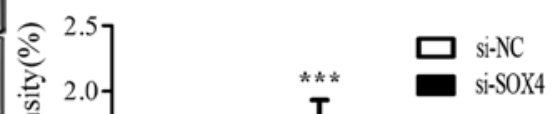

Si-NC Si-SOX4
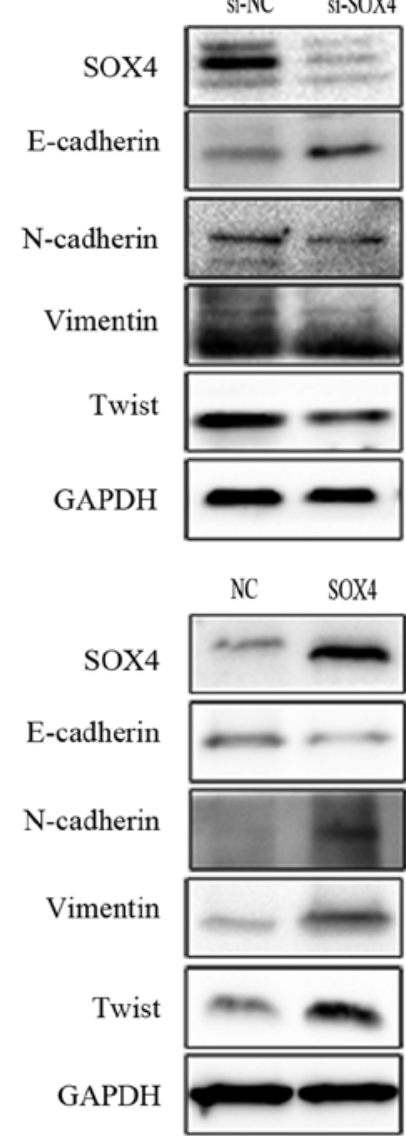
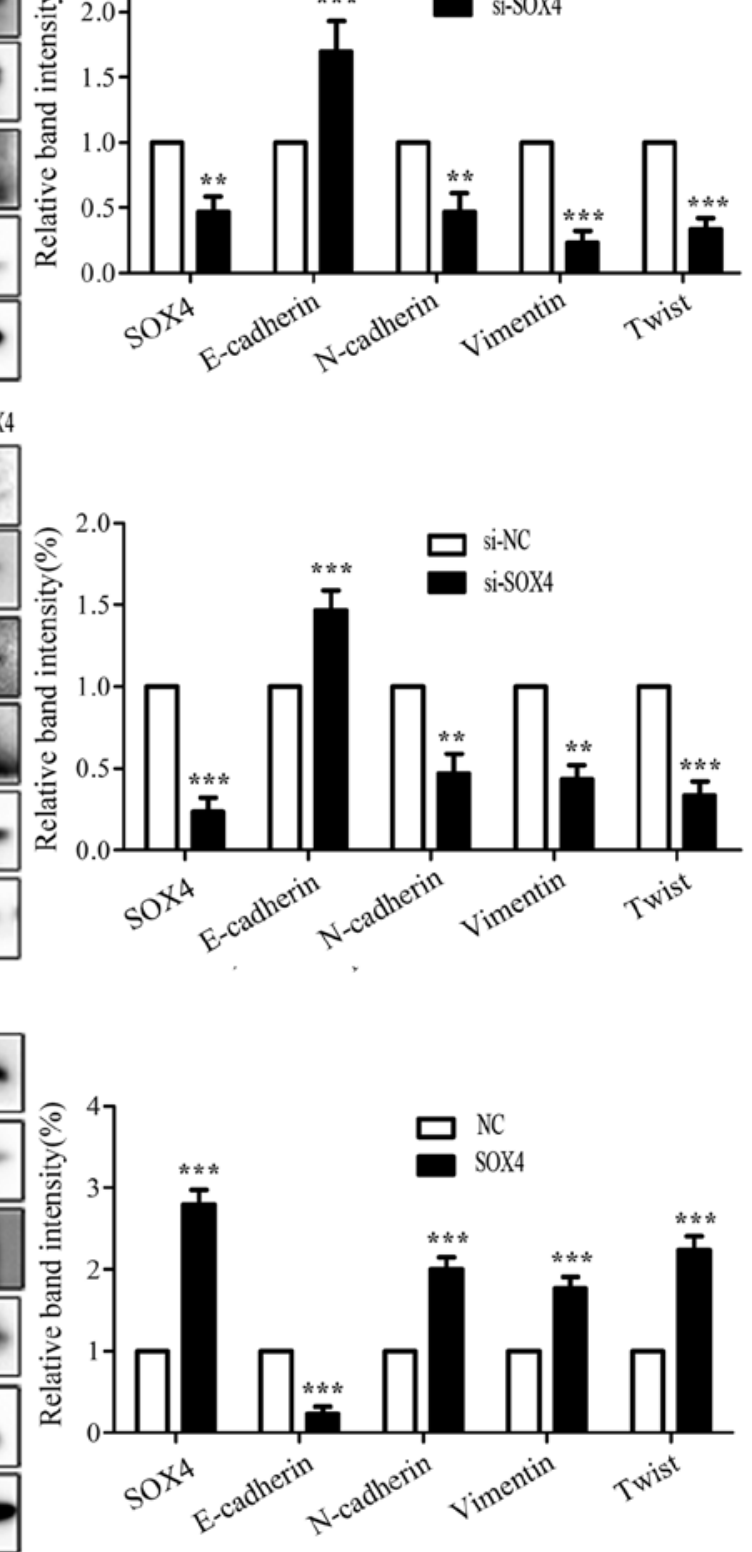

Figure 4. The effect of SOX4 on EMT profile in 786-O and SN12-PM6 and HK-2 cell lines in vitro. (A) The expression change of EMT markers in SOX4knockdown 786-O cells and corresponding control cells. (B) The expression change of EMT markers in SOX4-knockdown SN12-PM6 cells and corresponding control cells. (C) The expression change of EMT markers in SOX4-introduced HK-2 cells and corresponding control cells. Error bars represent mean \pm SEM from three independent experiments $\left({ }^{* * *} \mathrm{P}<0.001,{ }^{* *} \mathrm{P}<0.01,{ }^{*} \mathrm{P}<0.05\right.$, compared with the corresponding control).

western blotting the expression of several EMT markers in the 786-O and SN12-PM6 cells that were subjected to SOX4 knockdown. The results indicated that $786-\mathrm{O}$ and SN12-PM6 cell lines that were knocked down by SOX4 had a significant higher E-cadherin expression compared with corresponding control cells; whereas, the mesenchymal cell markers $\mathrm{N}$-cadherin, Vimentin, and Twist expression were prominently downregulated (Fig. 4A and B). To further corroborate the correlation between SOX4 and EMT, we then overexpressed SOX4 in HK-2 by using plasmid vector expressing SOX4, as confirmed by qRT-PCR and western blotting (Fig. 4C). Next, we examined the EMT markers expression in HK-2 cells that overexpressed the SOX4 by western blotting. As shown in Fig. 4C, the HK-2 of SOX4 overexpression exhibited a significant lower E-cadherin expression compared with the corresponding control cells; whereas, $\mathrm{N}$-cadherin, Vimentin, and Twist expression were significantly upregulated. These results suggested that SOX4 could induce EMT in RCC cell lines, and SOX4 knockdown could partially reverse EMT.

The effects of SOX4 knockdown and rescue on EMT expression profile in the 786-O and SN12-PM6 and HK-2 cell lines. To further substantiate the findings, we next performed SOX4 
A
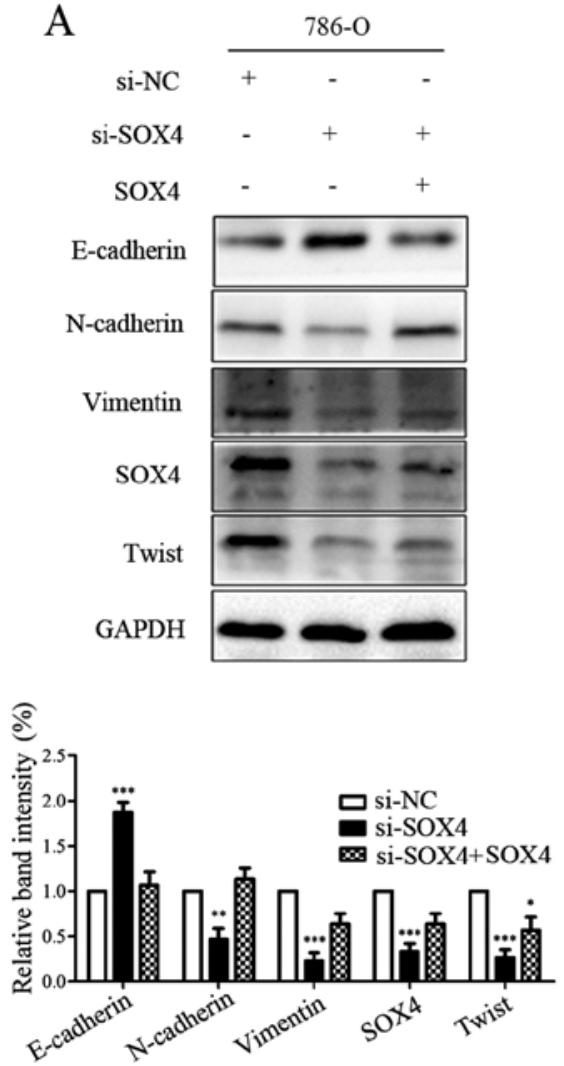

B
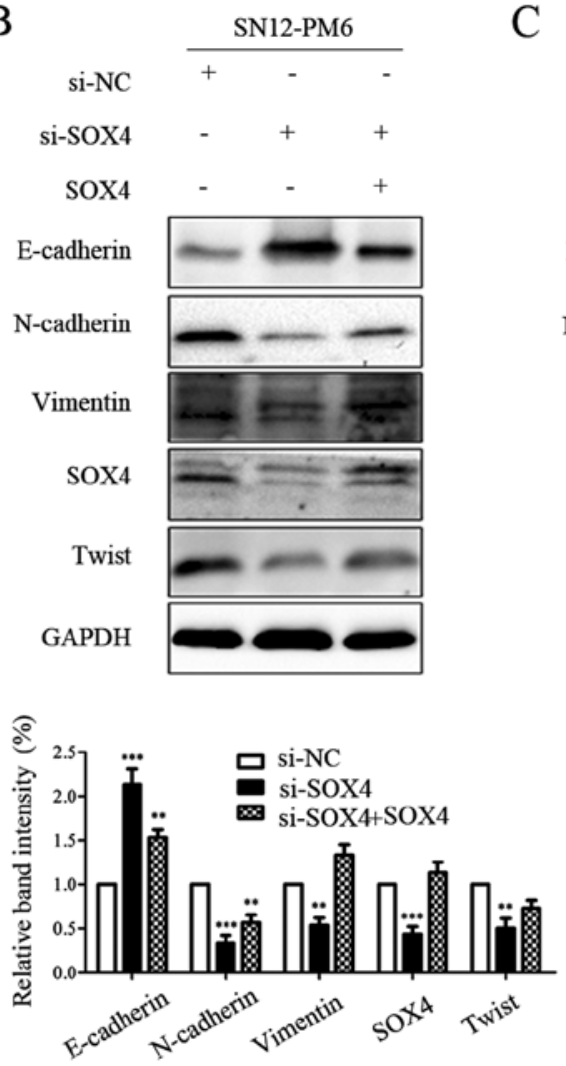

$\mathrm{C}$
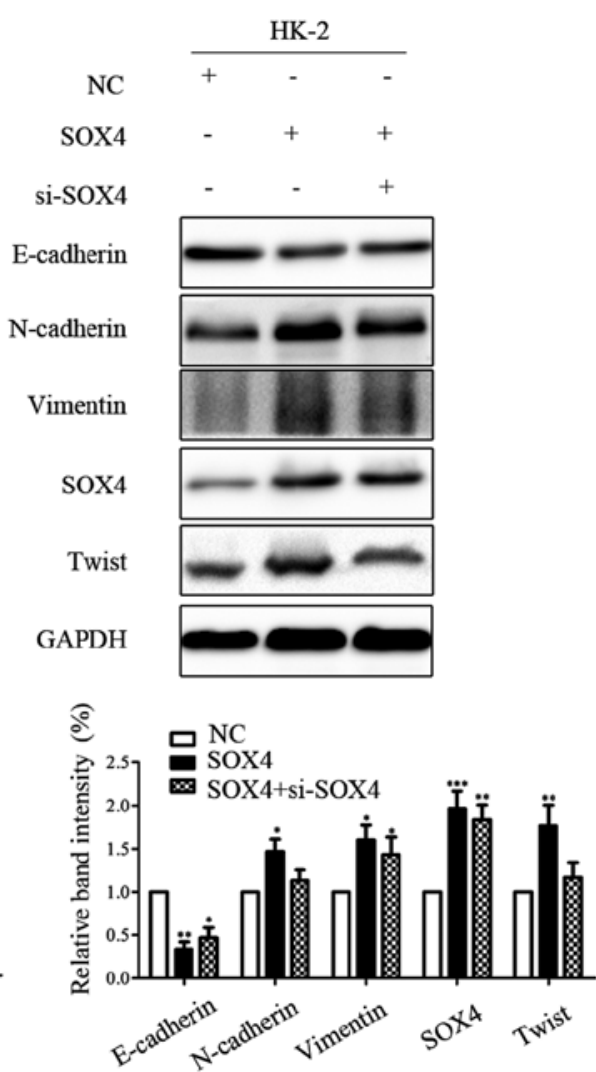

Figure 5. The effects of SOX4 knockdown and rescue on EMT expression profiles in the 786-O and SN12-PM6 and HK-2 cell lines. (A and B) The expression change of EMT markers after SOX4 upregulation in SOX4-knockdown 786-O and SN12-PM6 compared with corresponding control. (C) The expression change of EMT markers after SOX4 downregulation in SOX4-introduced HK-2 compared with corresponding control. Error bars represent mean \pm SEM from three independent experiments $\left({ }^{* * *} \mathrm{P}<0.001,{ }^{* *} \mathrm{P}<0.01,{ }^{*} \mathrm{P}<0.05\right.$, compared with the corresponding control).

knockdown and rescue tests in the 786-O and SN12-PM6 and HK-2 cell lines, respectively. As shown, in all the three cell lines tested, downregulation of SOX4 upregulated epithelial marker and downregulated mesenchymal markers in 786-O and SN12-PM6 and HK-2 cell lines; while overexpression of SOX4 yielded opposite effects (Fig. 5A-C). These results further solidified our findings that SOX4 could induce the EMT program.

SOX4 is an important component involving in TGF $\beta$ induced EMT. Multiple lines of evidence have confirmed the involvement of TGF $\beta$ signaling in EMT program. To further investigate whether SOX4 was involved in the process of TGF $\beta$ signaling-induced EMT in HK-2 cells, we stimulated HK-2 cells by using $2.5 \mathrm{ng} / \mathrm{ml}$ concentration TGF $\beta 1$ for 0 , 3, 7, 10 day(s). Compared with the parental HK-2 cells, the TGF $\beta 1$-treated HK-2 cells represented morphologic changes from cobblestone-like to fibroblast-like appearances (Fig. 6A). SOX4 expression was upregulated in HK-2 cells at mRNA and protein level, in a time-dependent manner following the addition of TGF $\beta 1$ into the cell culture medium (Fig. 6B and C). Moreover, TGF $\beta 1$ modulated the expression of EMT markers and p-AKT at protein level (Fig. 6C). These data indicated SOX4 might be an important component involving TGF $\beta$ induced EMT.

SOX4 induces EMT possibly via modulating expression of $p$-AKT. AKT signaling cascade has been reported involved in metastasis in a variety of cancers (33-35); Previous studies also showed that AKT pathway could induce EMT (36-39). To further explore the molecular mechanisms how SOX4 induces EMT and metastasis in RCC, we expanded our study to the metastasis-related protein $\mathrm{p}-\mathrm{AKT}$, which may be the potential downstream target of SOX4. As shown in Fig. 7A, SOX4 knockdown in 786-O and SN12-PM6 cell lines downregulated the expression of p-AKT, while overexpression of SOX4 in HK-2 cell line upregulated the expression of p-AKT (Fig. 7B). Furthermore, downregulation of $\mathrm{p}-\mathrm{AKT}$ was accompanied by the upregulation of E-cadherin, while upregulation of p-AKT reversed this result. Based on these results, we preliminarily established a pathway diagram that SOX4 modulated EMT (Fig. 7C). Collectively, these data indicated that SOX4 might contribute to RCC metastasis via modulating the AKT/EMT signaling cascade.

\section{Discussion}

Accumulating evidence indicates that the SOX4 transcription factor is significantly overexpressed in various human malignancies, including melanoma (40), leukemia (15), medulloblastoma (41), and caners of colon (19), prostate (17), breast (3), liver (18), and lung (16), indicating that it may play a crucial role in cancer initiation and progression. Previous study has reported that miR-335 suppresses breast cancer metastasis by directly targeting SOX4 (3). Moreover, SOX4 contributes to breast cancer progression through inducing EMT (21). In 
A

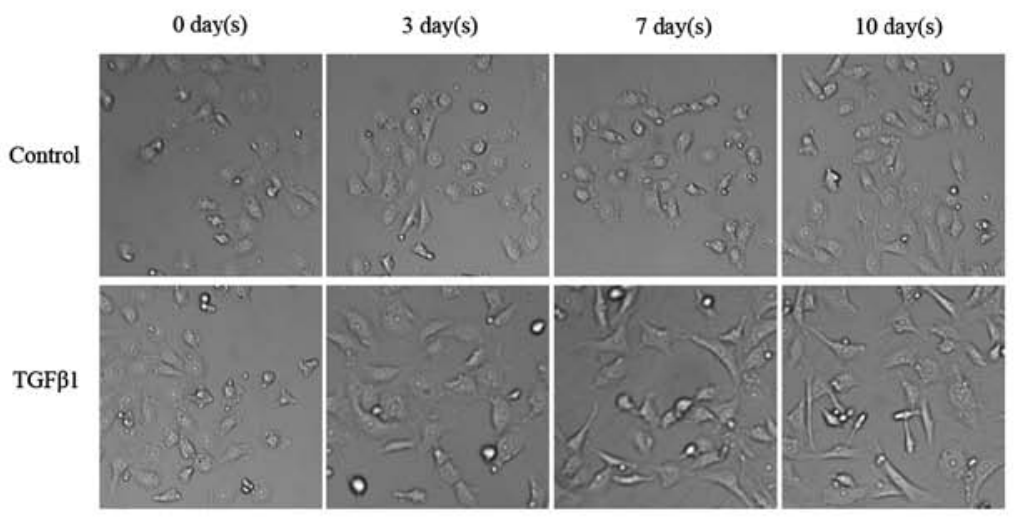

B

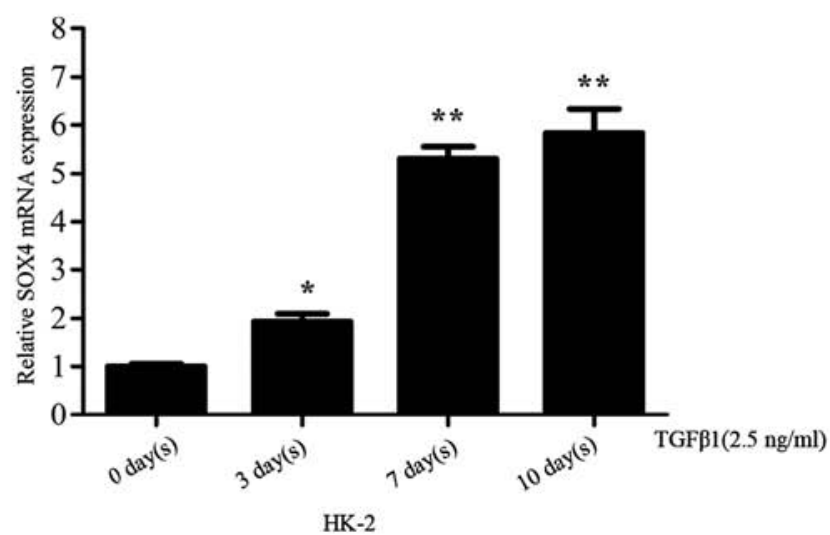

$\mathrm{C}$
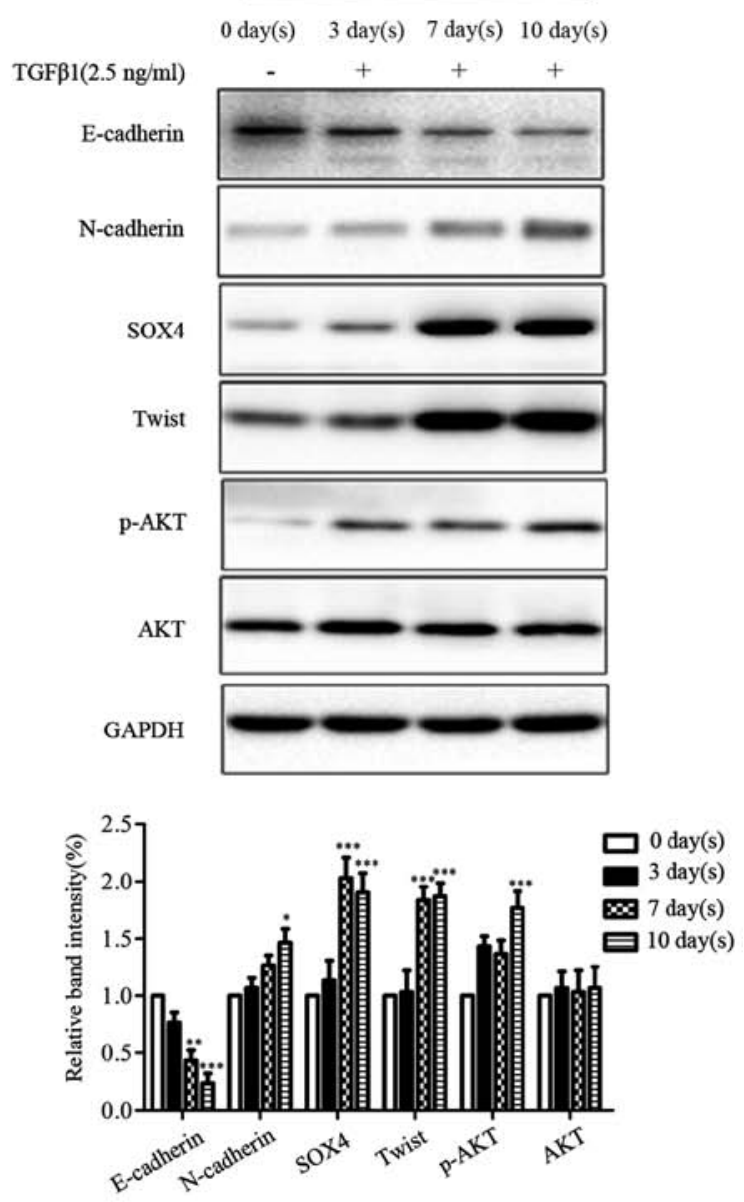

Figure 6. SOX4 is implicated in TGF $\beta$-induced EMT. (A) The morphology change of HK2 treated with control and TGF $\beta 1$ at indicated time. (B) The SOX4 mRNA expression change of HK-2 cells treated with TGF $\beta 1$ at indicated time. GAPDH was used as an internal control. (C) The EMT markers, SOX4, AKT and $\mathrm{p}$-AKT protein levels of HK2 cells treated with TGF $\beta 1$ at indicated time. GAPDH was used as a loading control. Error bars represent mean \pm SEM from three independent experiments $\left({ }^{* * *} \mathrm{P}<0.001,{ }^{* * *} \mathrm{P}<0.01,{ }^{*} \mathrm{P}<0.05\right.$, compared with the corresponding control).

endometrial cancer, SOX4 knockdown results in attenuation of endometrial cells growth; however, it has no effects on cell migration or invasion (42). In oral squamous cell carcinoma, SOX4 is involved in miR-204-modulated cancer stemness and EMT and promotes lymph node metastasis (43). In addition, knockdown of SOX4 expression induces apoptosis in adenoid cystic carcinoma (44). Conversely, SOX4 may significantly impair cell viability and promote cell apoptosis in the bladder cell line HU609 overexpressing SOX4 (24). Moreover, SOX4 may induce cell cycle arrest and promote cell apoptosis, and inhibit tumorigenesis in a p53-dependent manner in HCC116 cells (45). These studies suggest that SOX4 may play different roles in different malignancies. Different physiological function of SOX4 in different malignancies may be attributed to distinct tumor microenvironment and genetic background. However, the role of SOX4 in RCC is still unclear.

In our studies, we demonstrated that SOX4 expression was frequently upregulated in RCC tissues and cell lines, consistent with many of previous reports in other cancer types. Our results indicate that SOX4 may promote migration and invasion, which is consistent with the roles of SOX4 in breast cancer and oral squamous cell carcinoma. However, it has no effects on proliferation, apoptosis and colony formation in RCC. To understand the potential molecular mechanisms that SOX4 promoted RCC metastasis, we examined the EMT marker expression in RCC tissues and cell lines by qRT-PCR and western blotting. The results suggested that epithelial cell marker E-cadherin was downregulated at mRNA level and protein level in RCC tissues and cell lines; whereas, the mesenchymal cell markers $\mathrm{N}$-cadherin, Vimentin, and Twist were upregulated, indicating that EMT process happened in RCC progression.

Based on these results, SOX4 might promote migration and invasion of RCC through inducing EMT. Previous studies have confirmed that AKT signaling pathway could induce EMT through downregulating E-cadherin $(36,39)$. SOX4 was found to be elevated in prostate cancer and implicated in the activation of the PI3K/AKT pathway (46). Furthermore, the expression of SOX4 induced by PTEN loss could activate the PI3K-AKT-mTOR signaling in prostate cancer (17). Therefore, we investigated the expression of AKT and p-AKT in gain-of-function and loss-of-function assays of SOX4. The results indicated that the expression of p-AKT was positively correlated with SOX4 expression. Thus, we speculated that SOX4 might modulate AKT/p-AKT expression directly or 
A

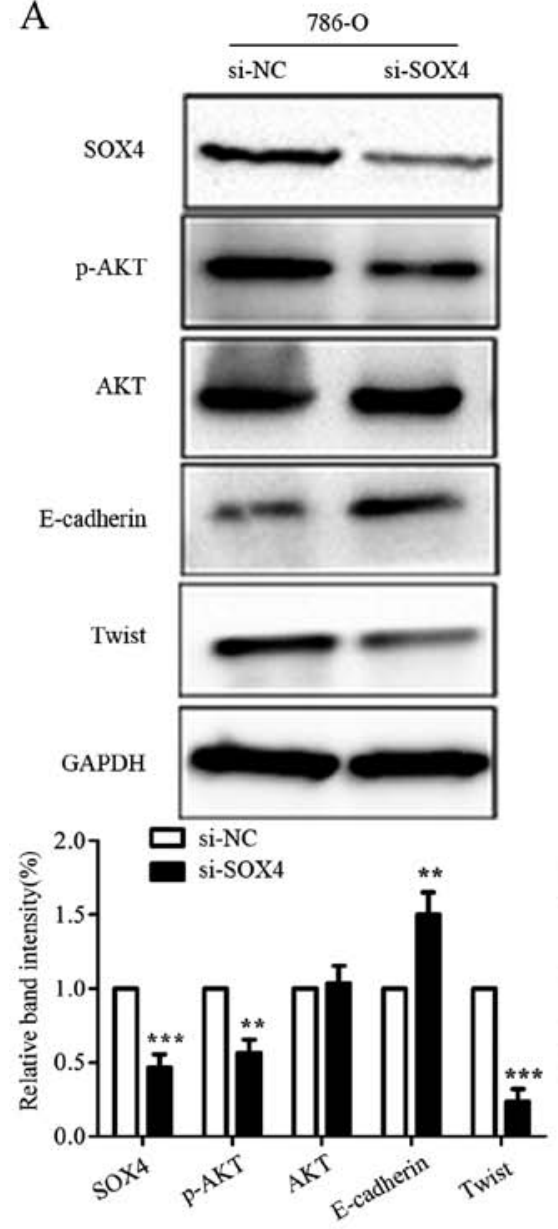

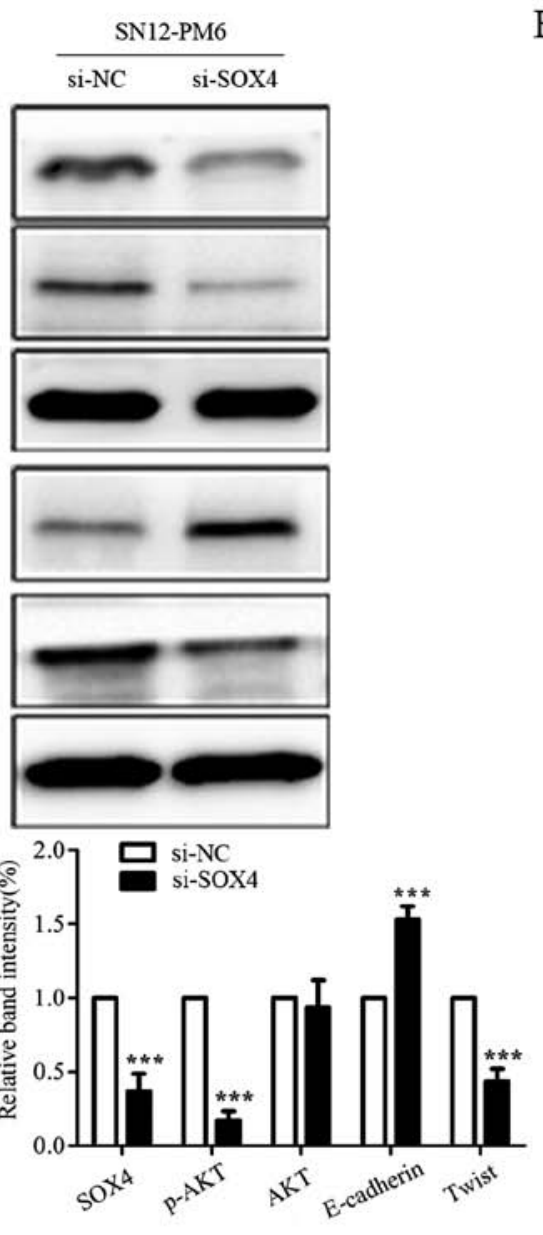

B

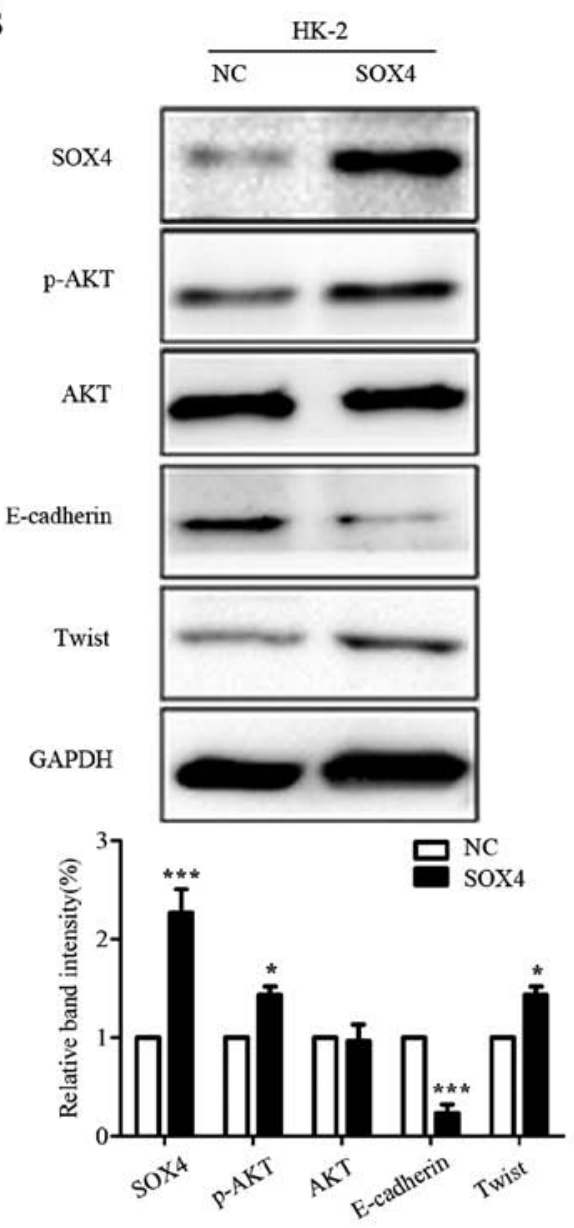

$\mathrm{C}$

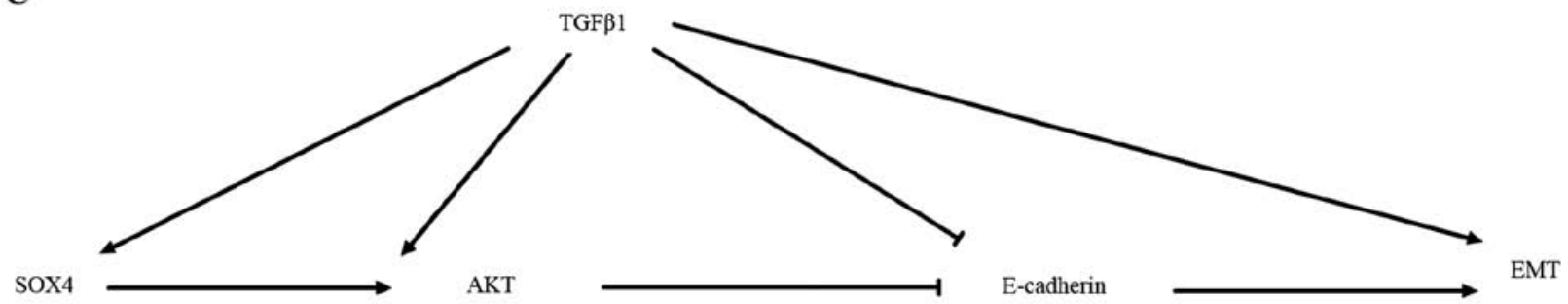

Figure 7. SOX4 induces EMT possibly through modulating p-AKT expression. (A) The AKT and p-AKT, EMT marker expression in SOX4-knockdown 786-O and SN12-PM6 cells. (B) The AKT and p-AKT, EMT marker expression in SOX4-introduced HK-2 cells. (C) The proposed pathway diagram of SOX4-AKTE-cadherin-EMT in RCC cells. Error bars represent mean \pm SEM from three independent experiments $\left({ }^{* * *} \mathrm{P}<0.001,{ }^{* * *} \mathrm{P}<0.01,{ }^{*} \mathrm{P}<0.05\right.$, compared with the corresponding control).

indirectly. However, there is a limitation in our study that the roles of SOX4 in vivo are not clear and what regulates SOX4 expression in RCC remains unknown. Therefore, future studies that explore the roles of SOX4 in vivo will further demonstrate the function of SOX4 in RCC.

In conclusion, the current study indicates that SOX4 is overexpressed in RCC tissues and cell lines. Moreover, our results demonstrate that SOX4 promotes migration and invasion of RCC by inducing EMT through AKT signaling cascade, which provides new insight into molecular mechanisms involvement in metastasis of RCC. Therefore, our study suggests that the function suppression of SOX4-AKT-EMT axis could be an attractive therapeutic intervention in RCC metastasis.

\section{Acknowledgements}

This study was supported by the National Natural Science Foundation of China (NSFC) (grant no. 81272560), the Open Research Foundation of the State Key Laboratory of Virology of Wuhan University (grant no. 2014KF007), Hubei Province Scientific and Technical Project (grant no. 2011CDB366), and Hubei Provincial Health Project (grant no. WJ2015MB020) to H.Y. This study was supported by the National Natural Science Foundation of China (grant no. 30872924, 81072095 and 81372760), the Program for New Century Excellent Talents in University from the Department of Education of China (NCET-08-0223), the National High Technology Research and Development Program of China (863 Program) (2012AA021101) 
to X.Z., and the Natural Science Foundation of Zhejiang Province (grant no. LY15H160052) to X.C.

\section{References}

1. Siegel RL, Miller KD and Jemal A: Cancer statistics, 2016. CA Cancer J Clin 66: 7-30, 2016.

2. Yang J, Mani SA, Donaher JL, Ramaswamy S, Itzykson RA, Come C, Savagner P, Gitelman I, Richardson A and Weinberg RA: Twist, a master regulator of morphogenesis, plays an essential role in tumor metastasis. Cell 117: 927-939, 2004.

3. Tavazoie SF, Alarcón C, Oskarsson T, Padua D, Wang Q, Bos PD, Gerald WL and Massagué J: Endogenous human microRNAs that suppress breast cancer metastasis. Nature 451: 147-152, 2008.

4. Hanahan D and Weinberg RA: Hallmarks of cancer: The next generation. Cell 144: 646-674, 2011

5. Thiery JP and Sleeman JP: Complex networks orchestrate epithelial-mesenchymal transitions. Nat Rev Mol Cell Biol 7: 131-142, 2006.

6. Pérez-Pomares JM and Muñoz-Chápuli R: Epithelialmesenchymal transitions: A mesodermal cell strategy for evolutive innovation in Metazoans. Anat Rec 268: 343-351, 2002

7. Thiery JP, Acloque H, Huang RY and Nieto MA: Epithelialmesenchymal transitions in development and disease. Cell 139: 871-890, 2009

8. Lamouille S, Xu J and Derynck R: Molecular mechanisms of epithelial-mesenchymal transition. Nat Rev Mol Cell Biol 15: 178-196, 2014

9. She ZY and Yang WX: SOX family transcription factors involved in diverse cellular events during development. Eur J Cell Biol 94 $547-563,2015$

10. Hong CS and Saint-Jeannet JP: Sox proteins and neural crest development. Semin Cell Dev Biol 16: 694-703, 2005.

11. Potzner MR, Tsarovina K, Binder E, Penzo-Méndez A, Lefebvre V, Rohrer H, Wegner M and Sock E: Sequential requirement of Sox 4 and Sox11 during development of the sympathetic nervous system. Development 137: 775-784, 2010.

12. Paul MH, Harvey RP, Wegner M and Sock E: Cardiac outflow tract development relies on the complex function of Sox 4 and Sox11 in multiple cell types. Cell Mol Life Sci 71: 2931-2945, 2014.

13. Sun B, Mallampati S, Gong Y, Wang D, Lefebvre V and Sun X Sox4 is required for the survival of pro-B cells. J Immunol 190: 2080-2089, 2013.

14. Hu G and Chen J: A genome-wide regulatory network identifies key transcription factors for memory $\mathrm{CD}^{+} \mathrm{T}$-cell development Nat Commun 4: 2830, 2013.

15. Zhang H, Alberich-Jorda M, Amabile G, Yang H, Staber PB Di Ruscio A, Welner RS, Ebralidze A, Zhang J, Levantini E, et al: Sox4 is a key oncogenic target in C/EBP $\alpha$ mutant acute myeloid leukemia. Cancer Cell 24: 575-588, 2013.

16. Medina PP, Castillo SD, Blanco S, Sanz-Garcia M, Largo C, Alvarez S, Yokota J, Gonzalez-Neira A, Benitez J, Clevers HC, et al: The SRY-HMG box gene, SOX4, is a target of gene amplification at chromosome $6 \mathrm{p}$ in lung cancer. Hum Mol Genet 18: 1343-1352, 2009.

17. Bilir B, Osunkoya AO, Wiles WG IV, Sannigrahi S, Lefebvre V, Metzger D, Spyropoulos DD, Martin WD and Moreno CS: SOX4 is essential for prostate tumorigenesis initiated by PTEN ablation. Cancer Res 76: 1112-1121, 2016

18. Liao YL, Sun YM, Chau GY, Chau YP, Lai TC, Wang JL, Horng JT, Hsiao M and Tsou AP: Identification of SOX4 target genes using phylogenetic footprinting-based prediction from expression microarrays suggests that overexpression of SOX4 potentiates metastasis in hepatocellular carcinoma. Oncogene 27: 5578-5589, 2008.

19. Sinner D, Kordich JJ, Spence JR, Opoka R, Rankin S, Lin SC, Jonatan D, Zorn AM and Wells JM: Sox17 and Sox4 differentially regulate beta-catenin/T-cell factor activity and proliferation of colon carcinoma cells. Mol Cell Biol 27: 7802-7815, 2007.

20. Yeh YM, Chuang CM, Chao KC and Wang LH: MicroRNA-138 suppresses ovarian cancer cell invasion and metastasis by targeting SOX4 and HIF-1 $\alpha$. Int J Cancer 133: 867-878, 2013.

21. Zhang J, Liang Q, Lei Y, Yao M, Li L, Gao X, Feng J, Zhang Y, Gao H, Liu DX, et al: SOX4 induces epithelial-mesenchymal transition and contributes to breast cancer progression. Cancer Res 72: 4597-4608, 2012.
22. Wang L, Li Y, Yang X, Yuan H, Li X, Qi M, Chang YW, Wang C, Fu W, Yang M, et al: ERG-SOX4 interaction promotes epithelialmesenchymal transition in prostate cancer cells. Prostate 74 : 647-658, 2014.

23. Wang C, Zhao H, Lu J, Yin J, Zang L, Song N, Dong R, Wu T and Du X: Clinicopathological significance of SOX4 expression in primary gallbladder carcinoma. Diagn Pathol 7: 41, 2012.

24. Aaboe M, Birkenkamp-Demtroder K, Wiuf C, Sørensen FB, Thykjaer T, Sauter G, Jensen KM, Dyrskjøt L and Ørntoft T: SOX4 expression in bladder carcinoma: Clinical aspects and in vitro functional characterization. Cancer Res 66: 3434-3442, 2006.

25. Zhang J, Jiang H, Shao J, Mao R, Liu J, Ma Y, Fang X, Zhao N, Zheng $\mathrm{S}$ and Lin B: SOX4 inhibits GBM cell growth and induces G0/G1 cell cycle arrest through Akt-p53 axis. BMC Neurol 14: 207, 2014.

26. Xu J, Lamouille S and Derynck R: TGF-beta-induced epithelial to mesenchymal transition. Cell Res 19: 156-172, 2009.

27. Wang T, Song W, Chen Y, Chen R, Liu Z, Wu L, Li M, Yang J, Wang L2, Liu J, et al: Flightless I homolog represses prostate cancer progression through targeting androgen receptor signaling. Clin Cancer Res 22: 1531-1544, 2016.

28. Xu S, Tao Z, Hai B, Liang H, Shi Y, Wang T, Song W, Chen Y, OuYang J, Chen J, et al: miR-424(322) reverses chemoresistance via $\mathrm{T}$-cell immune response activation by blocking the PD-L1 immune checkpoint. Nat Commun 7: 11406, 2016.

29. Chen X, Ruan A, Wang X, Han W, Wang R, Lou N, Ruan H, Qiu B, Yang H and Zhang X: miR-129-3p, as a diagnostic and prognostic biomarker for renal cell carcinoma, attenuates cell migration and invasion via downregulating multiple metastasisrelated genes. J Cancer Res Clin Oncol 140: 1295-1304, 2014

30. Huber MA, Kraut N and Beug H: Molecular requirements for epithelial-mesenchymal transition during tumor progression. Curr Opin Cell Biol 17: 548-558, 2005.

31. Guarino M, Rubino B and Ballabio G: The role of epithelialmesenchymal transition in cancer pathology. Pathology 39: 305-318, 2007.

32. Tiwari N, Tiwari VK, Waldmeier L, Balwierz PJ, Arnold P, Pachkov M, Meyer-Schaller N, Schübeler D, van Nimwegen E and Christofori G: Sox 4 is a master regulator of epithelial-mesenchymal transition by controlling Ezh2 expression and epigenetic reprogramming. Cancer Cell 23: 768-783, 2013.

33. Cho JH, Robinson JP, Arave RA, Burnett WJ, Kircher DA, Chen G, Davies MA, Grossmann AH, VanBrocklin MW, McMahon M, et al: AKT1 activation promotes development of melanoma metastases. Cell Rep 13: 898-905, 2015.

34. Kuo KT, Chen CL, Chou TY, Yeh CT, Lee WH and Wang LS: $\mathrm{Nm} 23 \mathrm{H} 1$ mediates tumor invasion in esophageal squamous cell carcinoma by regulation of CLDN1 through the AKT signaling. Oncogenesis 5: e239, 2016.

35. Niessner H, Forschner A, Klumpp B, Honegger JB, Witte M, Bornemann A, Dummer R, Adam A, Bauer J, Tabatabai G, et al: Targeting hyperactivation of the AKT survival pathway to overcome therapy resistance of melanoma brain metastases. Cancer Med 2: 76-85, 2013.

36. Larue L and Bellacosa A: Epithelial-mesenchymal transition in development and cancer: Role of phosphatidylinositol 3' kinase/ AKT pathways. Oncogene 24: 7443-7454, 2005.

37. Zhang PF, Li KS, Shen YH, Gao PT, Dong ZR, Cai JB, Zhang C, Huang XY, Tian MX, Hu ZQ, et al: Galectin-1 induces hepatocellular carcinoma EMT and sorafenib resistance by activating FAK/PI3K/AKT signaling. Cell Death Dis 7: e2201, 2016.

38. Julien S, Puig I, Caretti E, Bonaventure J, Nelles L, van Roy F, Dargemont C, de Herreros AG, Bellacosa A and Larue L: Activation of NF-kappaB by Akt upregulates Snail expression and induces epithelium mesenchyme transition. Oncogene 26 : 7445-7456, 2007.

39. Grille SJ, Bellacosa A, Upson J, Klein-Szanto AJ, van Roy F, Lee-Kwon W, Donowitz M, Tsichlis PN and Larue L: The protein kinase Akt induces epithelial mesenchymal transition and promotes enhanced motility and invasiveness of squamous cell carcinoma lines. Cancer Res 63: 2172-2178, 2003.

40. Talantov D, Mazumder A, Yu JX, Briggs T, Jiang Y, Backus J, Atkins D and Wang Y: Novel genes associated with malignant melanoma but not benign melanocytic lesions. Clin Cancer Res 11: 7234-7242, 2005.

41. de Bont JM, Kros JM, Passier MM, Reddingius RE, Sillevis Smitt PA, Luider TM, den Boer ML and Pieters R: Differential expression and prognostic significance of SOX genes in pediatric medulloblastoma and ependymoma identified by microarray analysis. Neuro Oncol 10: 648-660, 2008. 
42. Huang YW, Liu JC, Deatherage DE, Luo J, Mutch DG, Goodfellow PJ, Miller DS and Huang TH: Epigenetic repression of microRNA-129-2 leads to overexpression of SOX4 oncogene in endometrial cancer. Cancer Res 69: 9038-9046, 2009.

43. Yu CC, Chen PN, Peng CY, Yu CH and Chou MY: Suppression of miR-204 enables oral squamous cell carcinomas to promote cancer stemness, EMT traits, and lymph node metastasis. Oncotarget 7: 20180-20192, 2016

44. Pramoonjago P, Baras AS and Moskaluk CA: Knockdown of Sox 4 expression by RNAi induces apoptosis in ACC3 cells. Oncogene 25: 5626-5639, 2006.
45. Pan X, Zhao J, Zhang WN, Li HY, Mu R, Zhou T, Zhang HY, Gong WL, Yu M, Man JH, et al: Induction of SOX4 by DNA damage is critical for p53 stabilization and function. Proc Natl Acad Sci USA 106: 3788-3793, 2009.

46. Moreno CS: The Sex-determining region Y-box 4 and homeobox C6 transcriptional networks in prostate cancer progression: Crosstalk with the Wnt, Notch, and PI3K pathways. Am J Pathol 176: 518-527, 2010 . 